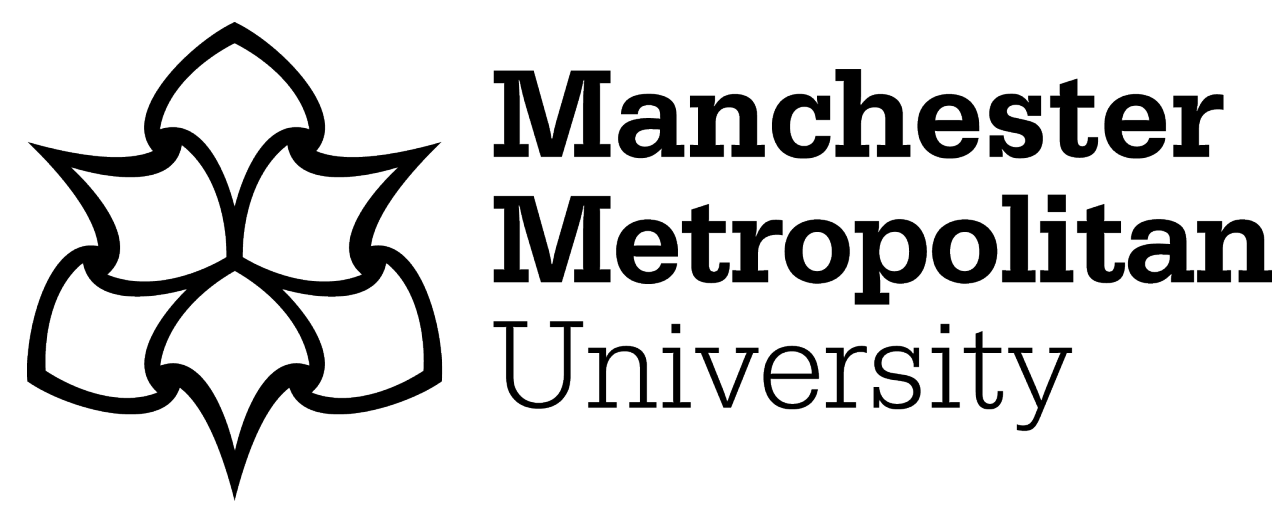

Skinner, Heather ORCID logoORCID: https://orcid.org/0000-0002-65058073 (2019) The impact of cultural values and economic constraints on tourism businesses' ethical practices. International Journal of Tourism Cities, 5 (2). pp. 169-187. ISSN 2056-5607

Downloaded from: https://e-space.mmu.ac.uk/621392/

Version: Accepted Version

Publisher: Emerald

DOI: https://doi.org/10.1108/IJTC-12-2017-0087

Please cite the published version 


\title{
The impact of cultural values and economic constraints on tourism businesses' ethical practices
}

\author{
Heather Skinner
}

\begin{abstract}
Purpose - Anecdotal evidence suggests that in times of economic constraints particularly in countries such as Greece that have long been stereotyped as corrupt, business practices amongst small- and medium-sized organisations that make up the majority of these nations' tourism operators may become less than ethical or legal. The purpose of this paper is to explore these issues empirically in order to understand the impact of both cultural values and economic constraints on tourism businesses' practices.

Design/methodology/approach - An exploratory case study using mixed methods has been adopted. Quantitative data were gathered from tourism business owners, managers and employees via questionnaires to establish the nature and scope of various unethical, illegal or immoral practices. Qualitative data were gathered to explore the ways these issues are considered and enacted.

Findings - Results show that there are many unethical and illegal practices that have been witnessed first-hand. Businesses' attempts at acting in an ethical and socially responsible manner tend to be affected by not only cultural issues, but also economic constraints, yet there remains a desire to act in a way that does not impact negatively on tourists or on the local society and environment.

Originality/value - This research fills a gap in the literature relating to the ethical stance and practices of tourism entrepreneurs. It also presents an original conceptualisation of these issues in light of their location within the extant literature on ethics, corporate social responsibility and both sustainable and responsible tourism.
\end{abstract}

Keywords Greece, Corporate social responsibility, Ethics, Sustainable tourism, Responsible tourism, Small- and medium-sized tourism enterprises (SMTEs)

Paper type Research paper

\section{Introduction}

Many Mediterranean tourism destinations that experienced a mass tourism boom period starting in the 1960s that continued up until the late 1980s and early 1990s are now in the late maturity stage of their product life-cycle, with some entering the decline phase. These destinations face challenges that have been brought about due to fewer tourist arrivals and/or decreased tourism expenditure. For resorts, the high season is increasingly shorter than in previous years, resulting in decreased profits to local resorts and tourism enterprises (Buhalis, 2001; Knowles and Curtis, 1999; Panayiotopoulos et al., 2016, 2017; Skinner, 2014, 2017; Tsartas, 2003). In some of these countries businesses are also faced with meeting increased austerity measures. For example, in Greece, businesses are increasingly being required to respond to higher levels of taxation, newly introduced taxes and strict capital controls (Visvizi, 2016). These challenges are impacting particularly hard on businesses operating in coastal and island destinations in this region, where tourism is often the main and sometimes only source of income for many residents.

Anecdotal evidence suggests that in times of economic constraints particularly in countries such as Greece that have long been stereotyped as corrupt, business practices amongst small- and medium-sized organisations that make up the majority of these nations' tourism operators may
Heather Skinner is based at the Business School, Institute of Place Management, Manchester Metropolitan University, Manchester, UK.
Received 28 December 2017 Revised 7 March 2018

23 May 2018

18 July 2018

Accepted 14 August 2018

(C) International Tourism Studies Association 
become less than ethical or legal. The aim of this paper is to explore these issues empirically in order to understand the impact of both cultural values and economic constraints on tourism businesses' practices.

Against this background, this paper explores the following research questions:

$R Q 1$. How do tourism enterprises perceive and enact social responsibility and ethical business behaviour?

$R Q 2$. To what extent are tourism business ethical practices affected by cultural values?

RQ3. To what extent are tourism business ethical practices affected by economic constraints?

Through a focus on small- and medium-sized tourism enterprises (SMTEs) this research makes an important contribution to filling a gap in the literature focusing on issues relating to the ethical stance and practices of tourism entrepreneurs "who have not been commended for their ethical business conduct" (Power et al., 2017, p. 47). The results from this research, therefore, contribute to our understanding of individual responses to ethical issues in a cultural context by examining notions of behaviour and responsibility, thus, filling the gap in the literature identified by Buckley (2012).

Zanfardini, Simó and Alcañiz (2013) recognise the importance of both the natural and cultural heritage of the places within which tourism businesses operate. As their work was undertaken in Spain, they suggest that these issues could be explored in other cultural contexts, particularly as they can be seen to affect loyalty to a destination. The research has, therefore, been contextualised by gathering the empirical data on the Greek island of Corfu, one of the top 10 tourist destination in Greece (Greek City Times, 2016), yet one that continues to face challenges similar to other destinations across the Mediterranean.

Hildreth (2007, p. 229) has found an "increasing focus on the 'functional city'" which is connected to the wider city-region or sub-region of that city's surroundings by "the ways that people live their lives between a city(s) and the towns and areas that surround it", thus signifying the appropriateness of studying cities within the context of the wider city-region. The link between smaller cities and their wider regions can be seen to be of relevance to this research given that around 56 per cent of the European Union's (EU) urban residents (which account for around 70 per cent of the entire EU population) live in small- and medium-sized towns (Servillo et al., 2017). A total of 38 per cent of the total EU population resides in small- and medium-sized cities (with populations of between 5,000-100,000), compared with only 30 per cent of the EU's population residing in cities of over 100,000 people (Hamdouch et al., 2017). Corfu has a total permanent resident population of only just over 100,000, of whom around 30 per cent live in its only city. Many of the formal aspects of civic life on the island can be undertaken only in the city, and so residents have to travel into the city in order to, for example, transfer vehicle ownership, pay taxes, deal with telephone and internet service provision, and carry out their personal and business-related banking. The municipality's main offices are located in the city (although there are smaller regional offices around the island, but many services can be performed only in the main city). As a tourist focused island, much of the island's entertainment and social life takes place in the city too, as many of the island's tourism resorts close outside of the tourist season and offer only very limited services for local residents throughout the winter months. The Municipal Theatre is located in the city, as is a ten-pin bowling centre, and many restaurants, bars and nightclubs. The island's small size affords relatively easy access to the city for all of the island's residents. On the other hand, many of the city's residents who work in the tourism industry travel out of the city during the season to work, and some to reside, in the island's tourism resorts. This typifies the conceptualisation of the territorial system relating to small- and medium-sized towns and cities as being part of both "urban and regional systems" and also linking with non-urban places (Sýkora and Mulíček, 2017, p. 439), thus reinforcing Bell and Jayne's (2009, p. 689) assertion that such smaller urban centres "can be more productively thought of in terms of influence and reach, rather than population size, density or growth". This research can also, therefore, contribute to the body of knowledge of tourism ethics of SMTEs in small cities and urban regions in Greece who may face similar challenges to those businesses in Corfu.

In a tourism context, CSR can be seen to encompass responsibility, sustainability and ethics (Zanfardini, Aguirre and Tamagni, 2013). Yet despite increasing interest in such issues in a 
tourism context these authors also stress that the literature on such issues remains sparse. Due to the broad theoretical underpinning of these topics, this research, therefore, also presents an original conceptualisation of these issues in light of their location within the extant literature on culture and tourism businesses, ethics and tourism businesses, corporate social responsibility, and responsible tourism and sustainability.

\section{Literature review}

A thorough consideration of business ethics per se is outside the scope of this paper (see Gaski, 1999; Hunt and Vitell, 1986, 1993 for a fuller consideration of the issues in a general marketing context). What is of relevance, and therefore what will be focused on in this paper, are considerations of both the deontological decisions behind SMTEs specific business practices, and the teleological evaluation of the consequences and impacts of these practices in a tourism context. Thus, cultural issues will also be considered, recognising that "there may be differing cultural perceptions of what is actually 'ethical' for a given society" (Skinner, 2005, pp. 263-4), as will economic issues, recognising the geographical context within which this research is being conducted.

\section{Culture and tourism businesses}

Successful organisational exchanges are those that are based on the shared values between parties to the exchange process (Maignan and McAlister, 2003). These include ethical considerations underpinning the "extent to which partners have beliefs in common about what behaviors, goals, and policies are important or unimportant, appropriate or inappropriate, and right or wrong" (Morgan and Hunt, 1994, p. 25). A socially responsible organisation is, therefore, one that displays an understanding of the common norms and shared values of all stakeholders. Thus, on the one hand "ethical principles are not subjective measures that vary with cultural, social, and economic conditions; they are objective statements that transcend countries, religions, and times. They are the basic rules or first principles that have been proposed to ensure a 'good society'” (Hosmer, 1994, p. 20). However, on the other hand, it is becoming increasingly difficult for organisations to base the exchange process upon shared stakeholder values and norms when dealing with cross-cultural norms and values in heterogeneous globalised markets, and also to deal ethically in globalised markets when, "in a cross-cultural environment, marketers are exposed to different values and ethical norms" and are less able to rely on "universally accepted ethical norms" (Nill, 2003, p. 90). Individual responses into cultural contexts, values, behaviours and responsibility has been identified as one of the three areas of highest priority for further study into sustainable tourism (Buckley, 2012, p. 536) where research progress has been low. One of the challenges faced by organisations attempting to understand the complexity of ethics in a globalised environment is that while culture is seen to be "an important determinant of ethical beliefs" (Hofstede, 1980, p. 103), cultural similarity between markets does not always indicate ethical similarity in business relationships (Singhapakdi et al., 2001). While tourists may be motivated to travel to experience different places with different cultures and ways of living that are different from their day to day lives, which remains "central to most forms of tourist experience" (Williams and Lew, 2015, p. 12), even tourists from countries that may be perceived as culturally similar (e.g. from geographically close EU nations) may not share the same ethical stance as their hosts. One example of this is the attitude towards free-roaming dogs, of which there is an increasing number in tourist destinations and in Greek towns and cities since the economic crisis. Tourists from countries and cultures that perceive dogs to be indoor pets, even as a part of the family, may find it very uncomfortable and upsetting to see free-roaming street dogs, and stray cats, or abandoned puppies and kittens when visiting tourist destinations where cultural values and beliefs that inform approaches to animal welfare differ from their own (Moorhouse et al., 2016; Popescu et al., 2017).

Corfu has an expatriate population of around 10,000 more or less full-time residents, comprising around 10 per cent of the island's total resident population. While the key source markets for tourism to the island remain the UK and Germany (Skinner, 2014), Corfu among many other Greek destinations is also favoured as a tourism destination by travellers from all over the world, including Greek domestic tourists travelling from the mainland. The city's port is also very popular with cruise ships, and in 2018 Corfu town itself is estimated to attract 650,000 visitors from cruise 
tourism alone (Enimerosi, 2018). Corfu, especially during the tourism season, is therefore highly multi-cultural, tourists visit from a wide range of different cultures and are served by people in tourism businesses from a wide range of cultures too. Increasingly tourism businesses are advertising for summer staff from various national groups, especially those able to speak the languages of their target customer markets. The island, therefore, also experiences an influx of resident workers from various different countries during the summer season.

Furthermore, while Corfu is now part of the Greek State, it has been so only since 1864. Prior to this, since the time of its first settlement in $734 \mathrm{BC}$, the island has been dominated by various cultures as it has been part of the Roman, Byzantine, Norman and Venetian Empires, it has been ruled by France, then Corfu fell to the Russians, then the Ottoman Empire, before France's second occupation in 1807. The island's culture is also heavily influenced by its time as a British Protectorate (1815-1864), and its geographical proximity not only to the Greek and Albanian mainland off its Eastern shores, but also to Italy to its West (Hopkins, 1977). Therefore, even tourists from the Greek mainland may find certain cultural differences when visiting the island. Yet Corfu does seem to share the same cultural stereotypes as the rest of Greece with regard to perceptions of corruption and poor business practices regarding legal compliance and business ethics that will be explored in more depth in the case study that follows.

\section{Ethics and tourism businesses}

SMTEs in general across this global industry, particularly with regard to issues of responsibility and sustainability, tend to be less well informed and able to access less information and resources than larger tourism businesses (Garay et al., 2017). Yet, despite the prevalence of small- and medium-sized businesses operating across all sectors of the tourism industry (Garay et al., 2017; Lashley and Rowson, 2010), there remains very limited research into the ethical practices of tourism entrepreneurs (Power et al., 2017). Research by Power et al. (2017, p. 36) has sought to understand not only "the ontology of ethical entrepreneurship", but also the mission, motives and virtues of ethical tourism entrepreneurs. However, while Power et al. (2017, p. 37) acknowledge previous research that claims in general "entrepreneurs are more ethical and socially responsible than most of the population" the constraints that may offer barriers to those operating SMTEs remains under-researched. The very "smallness" of these enterprises can lead to informality and flexibility of their operations, while also leading to difficulties enforcing regulations upon them (Power et al., 2017). Thus, ethics and social responsibility here are seen as two separate but linked concepts. A virtuous entrepreneur will act ethically due to his or her own values and beliefs about what is right and what is wrong. The smallness of the business also allows the individual's own ethics to drive their business practices more so than may be possible in larger organisations. Moreover, in its most simplistic sense, "virtuous" entrepreneurial behaviour is seen to be "connected to reward, whereas unethical behaviour is linked to punishment" (Power et al., 2017, p. 38). In terms of social responsibility, while ethics may guide the deontological decisions made about how the SMTE will behave, one key finding of Power et al.'s (2017) research is that the ethical entrepreneurs they interviewed focus more on the future than on the present. This would seem to suggest that smaller businesses may take the teleological consequences of their actions and their responsibility to society into consideration more than larger tourism enterprises.

\section{Corporate social responsibility}

In a recent review of research issues relevant to sustainable tourism relating to the "mainstream commercial tourism industry" Buckley (2012, p. 529) identified private sector responses to such issues include self-regulation and CSR to be of high practitioner interest with high levels of research progress.

Sainaghi et al. (2017) acknowledge that some of the metrics used to assess performance management in the tourism industry include environmental management, ethics and corporate social responsibility. However, there has also been seen to be a "prioritisation of relatively mechanical measurements of professed CSR activities, over more deliberative discussions of what actually constitutes CSR" (Farrington et al. , 2017, p. 31). While understanding the difficulty 
of enumerating and classifying CSR activities, especially as they would apply to the wide variety of businesses involved in tourism, to be genuinely considered as CSR, these activities should encompass the economic, legal and ethical expectations of society (Farrington et al., 2017). These activities should also go voluntarily above and beyond those required to keep within the law for business activities, and, moreover, the activities should be visible, and communicated to both internal and external stakeholders (Arvidsson, 2010).

Xu (2016) also recognises that a tourism organisation's CSR can impact on customers' perceived image of the company and also its impact on their brand loyalty. Zanfardini, Simó and Alcañiz's (2013) research proposed that such loyalty could also be extended to the destination, with tourists who perceive high or low levels of CSR associations extrapolating high or low levels of attitudinal loyalty accordingly to a tourism destination. These authors also found that tourists who perceive high levels of social responsibility in a tourism place tend to associate that with higher perceptions of quality. Thus, to at least some extent, CSR efforts can also be seen to indirectly affect tourists' satisfaction. However, Xu's (2016) exploratory research into Chinese domestic tourists' attitudes towards hotel policies and CSR found that not only did over 30 per cent of respondents not care whether or not the hotel undertook any CSR activities, but also that only 12 per cent believed that such activities were motivated towards the betterment of society, whereas 35 per cent of respondents believed motives were solely self-serving, to provide advertising and image-building opportunities for the very fact that CSR was being undertaken (the self-promoter's paradox - see Ashforth and Gibbs, 1989). Arvidsson (2010) found that it remains vital to include CSR in corporate communications, but that the communication of an organisation's CSR activities now seems to be more about being preventative in order to minimise value destruction than being about value creation. However, the question remains as to whether it is even possible to practice socially responsible business if a focus remains on profitability. Indeed, is CSR, as the argument is discussed in Farrington et al.'s (2017, p. 33) article "incompatible with the profit-maximising principles keeping businesses alive"?

\section{Responsible tourism and sustainability}

If ethics in the context of SMTEs are guided by individual entrepreneurs' beliefs about what is right and what is wrong, and appropriate/inappropriate actions, social responsibility can, therefore, be seen to be concerned with the impact of these actions on society and the environment. Marketing's responsibility for both the positive and negative impacts of tourism in a destination, the impact of ethical business practices on service quality, and tourists' attendant perceptions and practices were raised in a number of sessions at the 3rd International Congress on Ethics and Tourism (Apollo, 2017). Indeed, in many discussions on Responsible Tourism found in the extant literature, the onus of responsibility is placed more on the tourist consumer than the tourism business supplier. Sin (2016), for example, considers ethics and responsibility from the perspective of the tourist. Kim et al. (2017, p. 5) link the responsibility of the tourist to the ethical issues underpinning responsible tourism which then creates better tourism destinations by "protecting the environment, respecting local cultures, benefiting local communities, reducing pollution, and enhancing experiences". Mihalic (2016) believes that a focus on awareness, followed by the creation of an agenda as a blueprint for action, in economic, environmental and socio-cultural areas linked to sustainability understanding, can translate into more responsible tourism practices. Thus, although coining the rather clumsy term "responsustable tourism", Mihalic (2016, p. 469) proposes that "merging the words responsible (behaviour-based) and sustainable (concept and values-based) [...] fully reflects the academic and practical debate and action that is increasingly labelled 'responsible' tourism, yet de facto based on sustainability". There remain barriers to implementing tourism in a responsible and sustainable way. Yüksel et al. (2015, p. 119) summarised five themes when referring to Graci's (2008) study into such barriers in Indonesia that also appear pertinent to this research, namely:

Inadequate resources, particularly funds and information; lack of momentum from business owners; island culture and the isolation of sustainability issues from all other business aspects of the destination/organization; government bureaucracy and corruption; and physical attributes such as infrastructure impediments. 
Social, economic and cultural conditions vary across different countries. While on the one hand, ethical principles can be seen to transcend such issues (Hosmer, 1994), on the other hand, it is these varied social economic and cultural conditions that make the pursuit of normative ethics difficult to achieve, especially in tourism settings where host and guest cultures may vary dramatically on many levels. Moreover, while the tourism markets for Corfu are highly culturally heterogeneous during the tourism season, so are the people working in tourism businesses, and even out of season the expatriate community in Corfu accounts for 10 per cent of the island's full-time resident population. Yet even with the dominance of SMTEs in the industry, there remains limited knowledge about the ethical practices of such businesses. It is known that small business owners' ethical practices are driven by their individual values and beliefs (Power et al., 2017), yet Buckley (2012) found that it is such individual responses to issues surrounding responsibility that remain under-researched but of high practitioner and academic interest. It is also known that such responses, translated into business practices, impact on tourist perceptions not only of individual businesses, but can also impact on tourist perceptions of an entire destination. However, operating a wholly ethical and responsible business, whose actions go above and beyond what is required by law, can be costly and, therefore, difficult if not impossible to achieve for SMTEs (Farrington et al., 2017), especially those operating in countries such as Greece that have been heavily affected by the economic crisis and increasing austerity measures including increased taxation and strict capital controls (Visvizi, 2016). Furthermore, issues of responsibility can also be seen to rest with tourists themselves. The literature, therefore, also considers these issues from two dimensions, with Mihalic (2016) identifying these as being about sustainability, which is based on concepts and values, and responsibility, which is based more on actual behaviours. This research aims to consider both dimensions of concepts and behaviours to help further knowledge into both cultural values and economic constraints on SMTEs business practices.

\section{Methodology}

The majority of empirical papers considering business ethics in a hospitality and tourism context between 1995 and 2014 have been quantitative studies focusing on these issues in the hotel and general hospitality industry in developed countries (Köseoglu et al., 2016). It is, therefore, acknowledged that research based on a wider consideration of businesses within the industry, and also conducted from a mixed methods approach, could offer additional insights that could further knowledge of business ethics specifically in a tourism and hospitality context (Köseoglu et al., 2016). It is also proposed that the value of CSR research increases when it is contextualised within a specific industry (Farrington et al., 2017). Therefore, this research focuses not only on SMTEs, but on those located within a specific country, as this is likely to draw out issues raised regarding the culture within which ethical decisions are taken, while also considering the effects of ethical and illegal practices in that country. Based on similar reasons to Garay et al.'s (2017) research, this study also focuses on SMTEs, not only because of their sheer numbers in the tourism industry, but also because they tend to be able to draw less than larger businesses on resources and information regarding sustainability issues. This research is approached as an exploratory case study contextualised on the island of Corfu. The exploratory case study method is deemed appropriate when dealing with complex and contemporary phenomena in real-life contexts, especially where the complexity is attributable to the lack of clearly defined boundaries between a phenomenon and its context. In this respect, context becomes crucial to understanding the phenomenon. Such a method is also suitable to be used when events are unable to be manipulated. Multiple sources of both field and documentary evidence should be used. The exploratory case may often result in thick description, although such a method is not limited to, or characterised by, the use of qualitative data (Yin, 1989, 1994, 2009). Although undertaken from a mixed methods approach, this case does have a qualitative focus. The rationale for this is based on similar reasons to Power et al. (2017) who also explored ethics in SMTEs through gathering rich qualitative data.

\section{Case study: country context}

Buhalis (2001, p. 441) stresses that "Greece is one of the most remote, peripheral, insular and poor economic regions of the EU". Greece continues to rely upon tourism as a major contributor to its GDP, while still requiring improvements in the ways it manages and deals with tourism in 
both its public and private sectors, and the country's economy remains troubled. Greece has been in significant recession since the start of the economic crisis in 2008, with GDP dropping by over 27 per cent, rising unemployment, lowered levels of consumer spending and discretionary income, rising levels of poverty and homelessness, decreased investments and a shrinking private sector economy, where the majority of businesses are micro-businesses operating in the service sector, yet these businesses are "swamped by excessive taxation". The country is now seeing attendant effects of all these various social and economic crises upon both business ethics and culture (Visvizi, 2016). This is also seen in the decline in tourism which has had "dramatic implications to local economies" (Knowles and Curtis, 1999, p. 87) in countries such as Greece. Corruption is endemic across the business environment in Greece, and the Greek population tend to perceive government and public services as corrupt, untrustworthy, lacking in integrity and unethical (GAN Integrity, 2015). Indeed the country is ranked by the Organisation for Economic Co-operation and Development (OECD) as the 4th most corrupt developed nation (Chrysopoulos, 2016), although in a global context Greece is ranked in the top third (59th out of 180) nations overall in terms of transparency (Transparency International, 2017) Transparency International's indexing system of countries and territories that are perceived as very clean (scoring 100) compared to being perceived as highly corrupt (scoring 0), scores Greece 48 against a global average score of 43 , and a European average score of 34 . While there remain perceptions of corruption in Greece, according to global data (rather than data focused only on developed nations) the country is performing better than many of its European counterparts and has improved its public perception each year since 2012 when its score was only 36 .

According to the most recent census data, the island of Corfu has a permanent resident population of just over 100,000 . Roughly one third of the island's residents live in its only city which is also named Corfu (Kéркира in Greek). This sickle-shaped island is only around $32 \mathrm{~km}$ (20 miles) wide at its widest point along its Northern coast and is only around $64 \mathrm{~km}$ (40 miles) in length. Many of Corfu's residents travel regularly into the city from its wider whole-island region to go about various aspects of their daily lives, and during the summer tourist season many of the city's residents travel out into the island's tourism destinations to work, and some also to take up their summer work-related residence in these destinations.

The Geolab Institute of the Ionian University in Corfu held a conference in 2016 with an aim to place crime, particularly economic criminality, and corruption in the tourism-research agenda' recognising that to date these issues "have received relatively little attention in tourism scholarship" (Geolab Institute, 2016).

While the Prefecture of Corfu in recent times had been previously divided into 15 administrative municipalities, since 2011 it has reverted to one single administrative municipality within the Prefecture of the Region of the (seven) Ionian Islands. Thus, in terms of both government and governance, and in terms of both policy and practice, across the island as a whole there is a blurring of the boundaries of what is considered of relevance to only its main city and what to the island as a whole sub-region.

There are around 16,000 registered business in Corfu, of varying sizes, and ranging across four main sectors, which as defined by the Corfu Chamber of Commerce are: commerce, manufacturing, tourism and services (Figure 1).

\section{Sampling approach}

Statistics are not available on how many of Corfu's registered businesses are SMTEs. Therefore, a non-probability snowball sampling approach was taken to gathering both qualitative and quantitative data through the use of questionnaires. The researcher lives on the island and is well-connected with the Corfu Chamber of Commerce and the local business community. Respondents were initially purposively selected based on the qualification that they must own, manage or work for, a tourism enterprise that currently operates on Corfu.

\section{Survey instrument}

The questionnaire was structured in three sections. Section 1 was headed "about you and your business". This section asked mainly closed questions concerning the respondent and their 


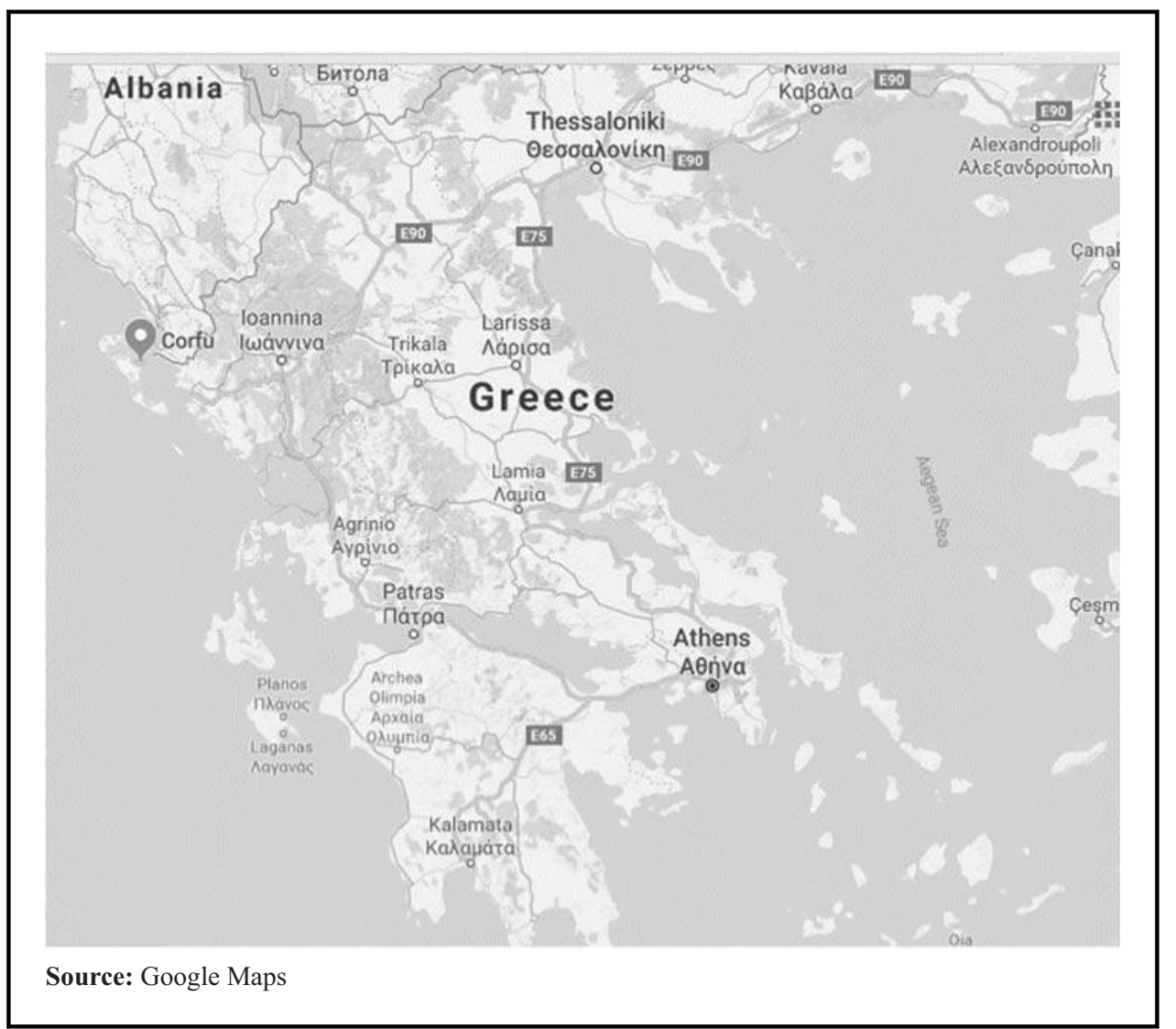

tourism business, i.e. what type of tourism business is the respondent involved with, their role (owner, manager, employee), how many people are employed by the business, the respondent's gender and age. An open question allowed respondents to state their nationality.

Section 2, headed "about illegal, unethical and socially irresponsible practices" was designed to gather quantitative data from a closed question listing 19 illegal and unethical business practices, and asking respondents to indicate which of these they had witnessed at first hand in the previous ten years. The options given to respondents in this question were derived mainly from publications outlining some of the unethical (i.e. immoral, illegal or harmful practices, Polyxeni and Katsoula, 2008) already recognised as happening in some tourism businesses in Greece in general or Corfu in particular. As derived from the literature, these included: tourists being overcharged for goods or services, differential pricing for tourists and "locals" and taxis not using the metre (Giannarou, 2017), tax fraud, bribery and a weak legal system (GAN Integrity, 2015), domestic animals being abandoned and/or mistreated (Moorhouse et al., 2016; Popescu et al., 2017), fly-tipping and rubbish being dumped into the sea (Skinner, 2016), goods or services being sold to young tourists under the legal age to purchase them, being sold illegal alcohol ("Bomba") or illegal substances (including laughing gas), and being sold goods or services while intoxicated (Williams-Burnett et al., 2016). However, other illegal and unethical practices were also listed in this question that had not been found within the literature, but which had arisen from various personal discussions the author has had with tourism businesses and tourists on the island, and found in discussions in online forums suggesting that other unethical practices on the island include bad customer service, business owners/employees talking negatively about customers behind their backs, smoking permitted inside public spaces, unlicensed and uninsured sellers/practitioners (e.g. beach/street sellers, massage on the beach), and business employees not being paid legally, paid late or their IKA (National Insurance) contributions not being paid. Although not arising from the literature but from more anecdotal sources, these 
matters were included in the survey in order to explore the issues empirically. An "other" option was also included for respondents to provide additional answers.

Section 3, headed "about your views of tourism ethics and social responsibility" was designed to gather qualitative data through three questions. The first question in this section asked "What does it mean to you for a tourism enterprise to be socially responsible and ethical?". The second questions asked "To what extent are tourism businesses' ethical and socially responsible practices on Corfu affected by cultural values and/or by economic constraints?". The final question in this section, which was therefore the final question in the data collection instrument, asked respondents "How does your tourism businesses try to ensure its actions are socially responsible and ethical and take into account the impact of its actions on all of its stakeholders?"

\section{Data collection and analysis}

Questionnaires were distributed in person and online initially purposively via the researcher's local contacts amongst SMTEs in Corfu. The snowball approach was then employed for further distribution of the online versions of the questionnaire. The questionnaire was available in both English and in Greek. All Greek responses were translated back into English for reporting in this paper, and the translation checked by a native Greek speaker.

Simple frequency descriptive statistics were analysed from the quantitative data that had been collected in order to identify the characteristics of the respondents and their involvement in various types of tourism enterprises, and the extent of the existence of illegal, unethical and socially irresponsible practices the respondents had witnessed at first hand over the past ten years. Rich thick description has been presented through an analysis of the qualitative responses gathered on respondents' perceptions of the impact of cultural values and economic constraints on tourism businesses' ethical practices.

\section{Analysis and discussion of findings}

Although only 60 questionnaires were returned, responses in this research were gathered from a much wider range of SMTEs than in previous studies that Köseoglu et al. (2016) identified had focused mainly on business ethics only in the hotel and hospitality industry (Figure 2).

All were small businesses (under 250 employees) the majority (90 per cent, $n=54$ ) were micro-businesses with between 1-9 staff, 4 had between 10 and 49 staff, while only 2 employed between 50 and 249 people. Responses were gathered from 39 males, and 21 females. Of these, 38 were business owners, 9 business managers and 13 employees. The majority $(n=52)$ were aged between 35 and 64, 7 were aged between 18 and 34, 1 was aged between 65 and 74 . Questionnaires were returned from Greek respondents $(n=17)$, respondents with dual nationality (Greek/British $n=2$, Greek/Dutch, $n=2$, Greek/French $n=1$, and Greek/American $n=1$ ) and ex-patriates (British $n=19$, Dutch $n=6$, Australian $n=2$, German $n=2$, Spanish $n=2$, American $n=1$, Canadian $n=1$, French $n=1$, Hungarian $n=1$, Irish $n=1$, and South African $n=1$ ).

There were no discernible differences in answers to either the closed or open questions according to gender, age or nationality of the respondents, by ownership, or by type or size of business. Where specific characteristics did seem pertinent (e.g. one response from a micro business stating that because of its size the issue of costs of implementing CSR were not as onerous as for larger businesses, or where a response from a Greek business owner related to insider insights about the country's culture) these have been indicated in the analysis where appropriate.

\section{Evidence of illegal, unethical and socially irresponsible practices}

Illegal, unethical and socially irresponsible practices were identified in both qualitative and quantitative responses. One employee mentioned "so many things that are not being done in most of the companies I have worked for [...] workers, clients and environmental issues that are not respected and, at least by law, should be". Another business owner believed that "some businesses take advantage of tourists". A business employee informed the study that "when I worked with a large Tour Operator they claimed to be into responsible tourism and customers 


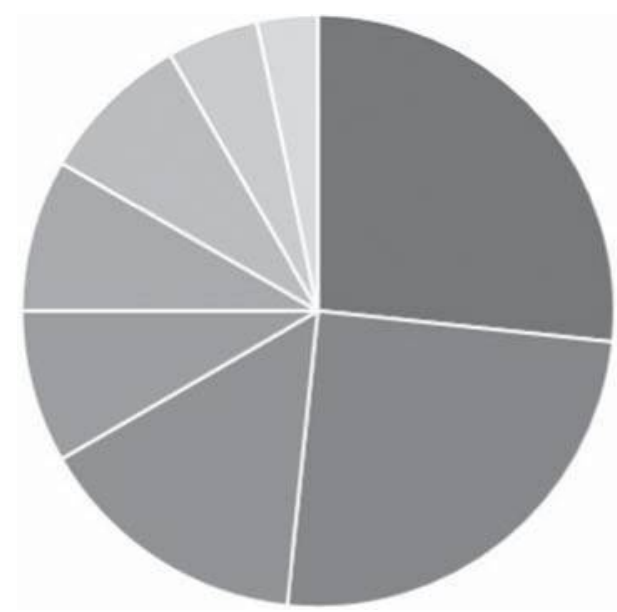

- Travel agent/excursions/transport/tourist information $n=16$

- Accommodation $n=15$

- Bar/Taverna $n=9$

- Local food/drink/craft products $n=5$

- Yacht charter $n=5$

- Sport/Culture/experience holiday services $n=5$

Tourist shop $n=3$

Tourist attraction $n=2$

had a small amount added to cost of holiday for that. However they did not practice their policy". One manager had received "no pay increase in 5 years", one employee had witnessed at first-hand "business owners lying to employees about their contract, IKA and other working conditions, not allowing them to take legal days off and changing their working shift in order to pay them less". Analysis of the quantitative data identified the illegal, unethical and socially irresponsible practices most frequently witnessed at first hand by business owners, managers, and employees over the last ten years (Figure 3).

\section{Figure 3 Illegal, unethical and socially irresponsible practices}

Young tourists provided with illegal substances (e.g. laughing gas) Goods/services being sold to young tourists under the legal age Tourists provided with goods/services while intoxicated Young tourists provided with illegal alcohol ("Bomba") Rubbish being dumped into the sea Animals being mistreated Tourism businesses not declaring all their taxable income Business owners/employees talking about customers Fly-tipping (illegally dumping rubbish or waste products) Taxis not using the meter Overcharging for goods/services Tourists not being provided with a receipt for goods/services Business employees not being paid on time Animals being abandoned (cats and kittens/dogs and puppies) Bad customer service Business employees not being paid IKA (Greek national insurance) Smoking permitted inside public spaces Unlicensed and uninsured sellers/practitioners Differential pricing (one price for "locals" another for "tourists")

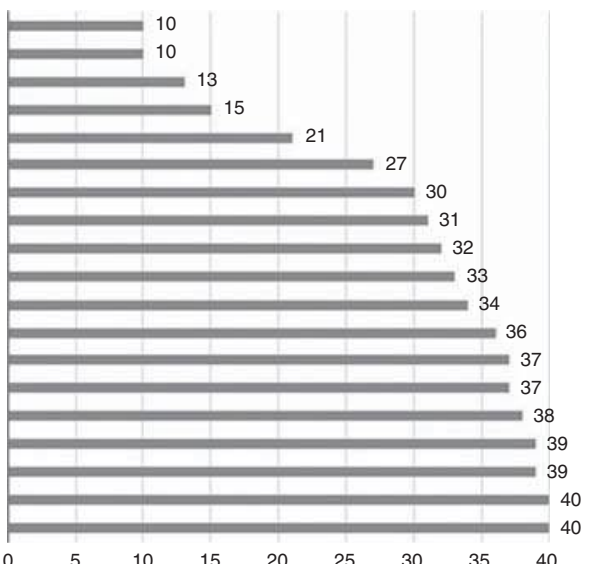

$$
15
$$

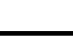




\section{How do SMTEs perceive and enact social responsibility and ethical business behaviour?}

One Greek business owner noted that "This is difficult to answer, because business owners here are not educated in this". This bears out Garay et al.'s (2017) findings that SMTEs seem to have less access to and information about issues of responsibility and sustainability.

Specifically with regard to the treatment of employees, respondents perceived that a socially responsible and ethical tourism business would have "good work practices", "employees are paid in time, enough and treated well", "working reasonable hours and having their time off, also in the season", staff would be treated "with dignity and respect", there would be "basic Health \& Safety in place", a business should "take care of the workers, make sure everything and everyone is/feels safe and secure, get paid, has health insurance, taxes are paid", the employees of the enterprise "should work according to the laws and be paid accordingly", "when you treat them well and support them you get it back from them":

In terms of social responsibility, responsibility towards employees must be a priority, as must honest and civil customer service. In terms of the wider community, businesses should try to work together for the good of the whole, rather than backstabbing or being indifferent towards the general situation. Corfu is in trouble - solidarity may be our only way out - and that can only happen when locals work together to keep good standards and mutual support systems.

And as one respondent noted, it can be enacted in practice:

I work for a company that pays well, better than most, and on time, while also paying its taxes and all legal obligations too. It can be done! We also try to be as eco-friendly as possible although we don't have much help from the system (lack of recycling).

When addressing environmental matters, it was perceived that socially responsible and ethical businesses should recycle and should "work more environmentally friendly [...] with respect for the natural beauty that is around them. Preserving and conserving what they have, which is their only true capital":

In terms of the environment, it is common knowledge that Corfu has a lot of problems where waste disposal is concerned. However, businesses that do produce waste (mine does not), should try to minimise where possible and be part of the solution.

I would expect to be aware of the social/environmental policies and practices in the everyday practices and attitudes. I would want to know there were environmental practices such as recycling and use of solar and wind energies where possible.

While issues of "sustainability" were not mentioned explicitly by respondents, the concept of sustainability in terms of societal and environmental impacts of SMTE business practices did arise. This may indeed be a reflection of the notion raised by Mihalic (2016) that what is often labelled as sustainable in a tourism context equates to responsibility, although sustainability tends to relate more to conceptual values-based ideals, with responsibility relating much more to actual behaviours.

Responses also linked the notion of ethics and social responsibility to customer perceptions about the business (Xu, 2016; Zanfardini, Simó, and Alcañiz, 2013). It was perceived that socially responsible and ethical businesses should "always treat tourists in the same way we would like to be treated. Always try to improve", "provide services that comply to a quality/price relation, while not deteriorating the local environment but underlying and bringing out the local character", "treat their customers correctly and politely in a friendly manner always. The customer is the person coming in to spend his money and should be treated with respect", "More tourists are going to come if they have a good service", "That's the way to keep your clients happy and satisfied. So you have repeaters and word of mouth advertisement", "I have been a business owner for 15 years here and have always had happy guests because I describe accurately, give excellent support and feedback and receive in return 5 star reviews".

One Greek business owner found that the best way to manage meaningful stakeholder relationships was to consider the consequences of all their business actions and obligations "towards the State, society and workers", to evidence "respect for our customers", to ensure employees are offered a "safe and non-discriminatory working environment" and to consider the way the business operates in terms of "care for society and the protection of the environment". 
Other responses suggested that this can be managed "by being closely networked with local stakeholders such as small businesses and local communities so as to understand what impact our business can have in a positive sense and where possible avoid negative impacts", and "by constantly looking for the best solution to the given challenge, taking into account the staff, the guests, the local stakeholders in the village, the laws and culture of the country":

My business ensures that suppliers and employees are paid up-front. All deals are made by mutual agreement, and we forge trust-based relationships with all our associates with a view to long-term collaboration. We go beyond the call of duty where customer service is concerned [...] We emphasise the collective good, function as a collective, and support all our associates in their endeavours, whether or not this is reciprocated (e.g. mutual advertising, word of mouth promotion, good communication, timely payment [...]). And we have minimal environmental impact. The nature of our business is such that we are able to do this - but we do know that not everyone can, and we are tolerant towards those who cannot - as long as individuals (esp. employees) are not harmed.

Respondents also recognised that ethical and socially responsible business practices can come at a cost, for example, seeking to use "ethically sourced materials and using local suppliers despite the higher cost", or recognising that compliance with the law and taxation requirements may affect profitability:

I stay within the law and declare and pay my tax and other charges lawfully even if it means less profit.

However, on the other hand, this may not be perceived as much of an issue for a micro-business than for larger tourism enterprises:

We are a very tiny business with no employees which is how we are able to be profitable. We take good care of our guests and intentionally charge below market rate so its affordable for guests to eat at restaurants and shop.

Bearing out Power et al.'s (2017, p. 37) findings concerning the way an entrepreneur's own ethics drives their business practices, some business owners identified their own personal values with the way they practice business:

We are good people and try to manifest this in all our actions, not always successfully, but we are trying.

Honesty, faithfulness, being genuine, being socially aware, being myself.

I don't cheat, lie, or steal from my clients.

We recycle plastic bottle tops and encourage guests to do so.

Yet generally there was little mentioned concerning the onus on the tourist to act responsibly. Where this issue was raised, it generally concerned tourists seeking low cost rather than high quality, complaining if beer prices were raised by a few cents, or not seeking to engage with local culture (Kim et al., 2017), asking for "chips with everything" rather than consuming authentic local food:

Everybody wants chips, some people don't want to try the tzatziki.

If you pay everything you're supposed to pay you'll never make any money, that's the problem, ask everybody, you have to pay out and then people come in and complain you've raised the price of beer by 20 cents.

As well as what a business should do to be ethical and socially responsible, responses also identified what businesses should not do:

Not to exploit anyone be they employee, customer, local, or another business in particular local small businesses; not going into direct competition with someone who relies on the income from that business to live.

\section{To what extent are SMTEs' ethical practices affected by cultural values?}

Responses to this issue were mixed. Some respondents stressed that cultural values across Corfu were not always perceived as contributing positively toward ethical practices. These included the way businesses react negatively to competition from other SMTEs, not always paying attention to laws, especially if that means tourist would not otherwise get the 
holiday they want or expect (e.g. bars opening and not observing "quiet time" during the daytime siesta period, allowing smoking indoors, or staying open and playing music later than is allowed), and also tax avoidance and evasion, not only because of the current economic crisis, but historically, embedded in the local culture:

I think for many years businesses made easy money in tourism and now that the standard has gone up people expect more, there is with many an unwillingness to change [...] Luckily this is not everywhere. Of course economics play a part in these practices - there is very little incentive for people to be, for example, honest about their tax returns.

Local cultural values sadly include strong negative competition, and there is little collective solidarity or understanding that bad publicity harms everyone.

Some businesses identified a temporal aspect to the issues:

Since the early 90 s I have never seen any evidence of business owners/managers of businesses being proactive in terms of ethics and social practices. Greek people seem to be steeped in tradition and definitely constrained by the current climate.

Other responses noted that practices are improving over time, and things are not as bad nowadays as they may have been previously:

Of course all are in the business to make a fast buck when they can and cheating on prices [...] is I

believe still a common practice as is the lack sometimes but not so much as 10 years before.

Some responses perceived that the culture of the place was a positive element, although these also recognised that the enduring economic crisis may be having an additional effect on business practices:

Generally I feel the cultural values are a positive influence but increasingly the economic restraints appear to be placing the continuation of those cultural values under threat [...] the cultural values of the people of Corfu that make it the place it is.

One Greek business owner stated that while both cultural and economic factors do indeed affect business practices "they are but they shouldn't. A new ethos is emerging in which ethical and socially responsible practices are self-evident".

\section{To what extent are tourism business ethical practices affected by economic constraints?}

Economic constraints are seen to have a huge impact on ethical practices. Increased austerity measures implemented across Greece are increasing the number of taxes and raising the level of taxation a business must pay, while adding in new legal requirements with which businesses must comply, often as a way of enforcing the new taxes. Thus one business owner identified that "it is hard with the current rules and regulations to operate in a fully legalized and ethical way without paying way too much money". Another Greek business owner stated that "the economic constraints during the 'crisis years' have been almost unbearable for people who try to hold an ethical and socially responsible business". This bears out Farrington et al.'s (2017) concern that given the costs associated with implementing CSR, it may be impossible for businesses to practice social responsibility and remain profitable.

Moreover, businesses recognise that economic constraints can not only affect service quality but will also have an effect on employee pay:

A lot of businesses have to pay so many taxes that they are pushed to crop the quality of their work. The wages are so low that people don't work with pleasure. Businesses in Greece never get support from the state so the money they pay for their taxes gets lost.

That businesses do not perceive they get anything back from the state from the amount of taxes they pay, and with a shortening season, decreased tourism numbers and decreased tourism spend as seen in other similar Mediterranean destinations, coupled with a rather lax historic attitude toward compliance with tax regulations, led one Greek business owner to explain:

Since 2010 we have to do this to survive - we are overtaxed now, with all the different taxes it can go up to $86 \%$. All-inclusives have squeezed our incomes down. And, when the season is so short, with all the taxes now, we really only get income from 40 days work a year - we need 'black money' to keep going. 
An alternative would be for the State to make taxation levels more reasonable:

If they could make tax more reasonable they'd find people would be happier to pay it, but in Greece people have been avoiding paying tax for years.

The effects of what are perceived as being overly onerous legislative requirements and overly heavy taxation were also identified as having a particular detrimental effect on SMTEs:

People are often working far beyond their comfort level not having a day off for many months which is exhausting but necessary to survive. This would not be the case if the taxes were more in line with what is logical and affordable for the businesses.

There are those who want to follow both legal and ethical considerations, but simply cannot survive if they do so. The current taxation laws are crippling small businesses and need urgent reform if they are to survive.

This is mainly influenced by the economic crisis and the suffocating limits imposed on small/medium-sized businesses. For example, many small businesses who want to insure their employees cannot, because the insurance premiums are disproportionately high in relation to their profits.

Corfu's SMTEs do seem to recognise that socially responsible organisations display an understanding of the common norms and shared values of all of their stakeholders (Maignan and McAlister, 2003; Morgan and Hunt, 1994). While the quantitative findings suggested that many illegal, unethical and socially irresponsible practices continue to be witnessed at first-hand across the island, the qualitative findings suggested that there are common areas of shared understanding concerning what should constitute normative ethical practices, and this focused overwhelmingly on the concept of "respect". To be socially responsible and ethical, businesses should have respect for the social and cultural environment within which they operate, respect for the economic environment within which other SMTEs operate, to respect the laws, including paying relevant taxes, to respect suppliers, employees and to respect tourism customers, and to respect the natural environment. Moreover, in agreement with Farrington et al. (2017) that social responsibility should encompass the economic, legal and ethical expectations of society, and as outlined by Arvidsson (2010), responses also identified that to be socially responsible and ethical meant a business should go over and above what is required by law. Answers to open questions generated responses that businesses should also show respect for society through engaging in voluntary and charitable efforts outside of their main business focus - to give something back to society and those whom the government is not helping, and to give a proportion of profits, produce and services to those in need, and to participate proactively in initiatives that could have a positive effect on both environmental and social issues. It was, therefore, also deemed to be important for SMTEs to seek to use "local products at all times".

Answers to open questions all stated that to be a socially responsible tourism business the enterprise should consider the natural, social, cultural and economic environment within which it operates, and work according to set of values that respect all of these elements. However, when it comes to behaviours, it was important to identify the ways in which tourism businesses act and take into account the impact of their actions on stakeholders.

In summary therefore, and as displayed in the original conceptualisation of these issues below (Figure 4) the individual ethics of SMTEs and tourism entrepreneurs guide their actions which are affected by the natural, social, cultural and economic environments within which their businesses operate. These actions, translated into CSR activities in particular or social responsibility in general, in turn have an effect on these environments. Similarly, the individual ethics of tourists are not only affected by the environments from which and to which they travel, but are also affected by the social responsibility of the tourism businesses within these destinations. Efforts towards sustainable tourism can then be seen to be affected by the values of both tourists and tourism suppliers, while their behaviours can be seen to fall within the realm of responsible tourism.

\section{Conclusion}

Anecdotal evidence had suggested that in times of economic constraints particularly in countries such as Greece that have long been stereotyped as corrupt, business practices may become less than ethical or legal. Moreover, that this may be more prevalent amongst SMTEs 


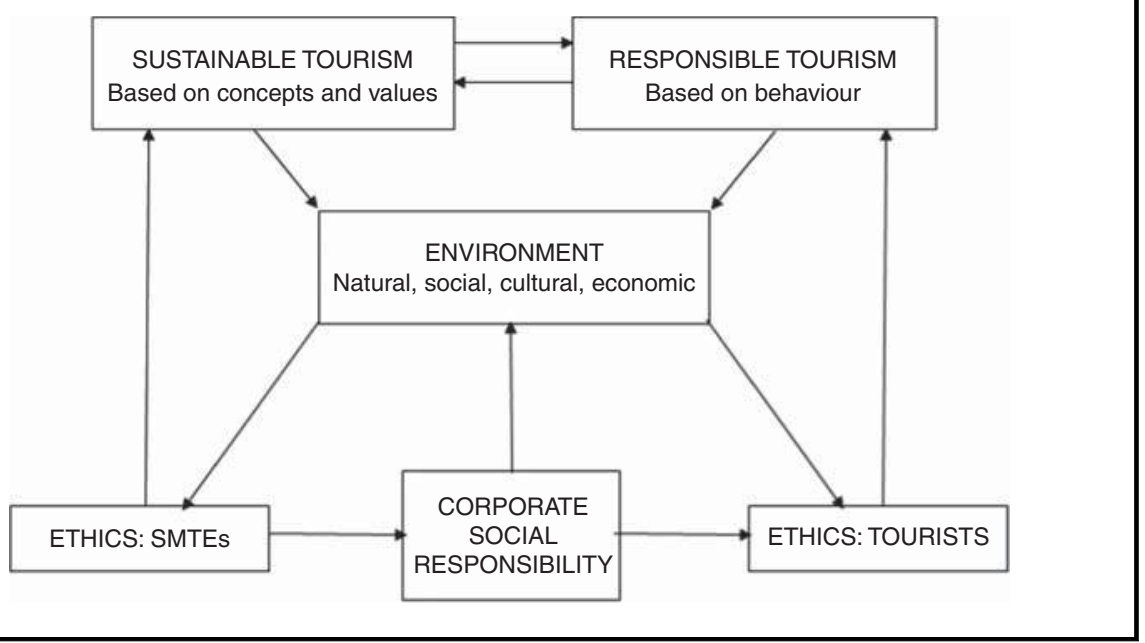

(Power et al., 2017) that make up the majority of these nations' tourism operators. This research has, therefore, explored these issues empirically in order to understand the impact of both cultural values and economic constraints on tourism businesses' practices, thus contributing to gaps in the literature that concern the ethical stance and practices of tourism entrepreneurs in a cultural context (Buckley, 2012; Zanfardini, Simó and Alcañiz, 2013).

Although based on only a relatively small sample, this research has informed the debate on tourism ethics through gathering responses from a much broader range of SMTEs than has been found in previous studies that have tended to focus on businesses operating in the hotel and hospitality industry (Köseoglu et al., 2016).

Contextualising the research in a specific country has also allowed this study to better inform issues relating to the cultural environment within which socially responsible and ethical business is both perceived and enacted. In conclusion, this paper addressed three specific research questions, and has found the following:

$R Q 1$. How do tourism enterprises perceive and enact social responsibility and ethical business behaviour?

In the context of Corfu, this study found that for a tourism enterprise to be socially responsible and ethical means to base its actions on respect - for employees, tourists, other businesses, society as a whole and the natural environment, and doing so in a way that goes over and above legal requirements, taking consideration of the effect of its business practices on all stakeholders, not just being proactive in ensuring its actions may impact positively but also ensuring its actions do not societal or environmental harm:

$R Q 2$. To what extent are tourism business ethical practices affected by cultural values?

Those SMTEs that participated in this research identified the cultural factors in general across Greece, notably as implied by Polyxeni and Katsoula (2008) and Visvizi (2016) of an historic reticence to pay tax, and also a lack of understanding concerning the impact of business practices on the natural and social environments within which these businesses operate.

Responses also identified some of the difficulties of acting in a socially responsible way given the increased regulation and taxation levied against them due to increased austerity measures (Visvizi, 2016), thus implying that economic constraints are impacting on business practices across Greece for this reason.

Although it is recognised that in some cultural contexts, such as on the Greek island of Corfu, culture does impact on business practices, specifically in this instance a cultural history of tax avoidance and evasion since the heydays of the tourism boom, and a competitive rather than 
cooperative business culture between SMTEs that may have been exacerbated by the island's declining tourism numbers, revenues and season length:

RQ3. To what extent are tourism business ethical practices affected by economic constraints?

Moreover, the Greek island of Corfu has suffered an economic crisis since 2010 that has seen increased austerity measures imposing additional laws and taxes on small businesses that are not always in a position to meet these requirements and stay profitable. Thus, while many businesses want to act in a socially responsible and ethical manner, to do so could lead to the end of a business completely if this means losing profitability. However, not doing so can impact negatively on tourists' perceptions of the business which in turn could lead to a lack of sustainability of the business anyway.

This research has also, therefore, made a contribution to filling previously identified gaps in knowledge concerning tourism, CSR, responsibility, sustainability and ethics (Zanfardini, Aguirre and Tamagni, 2013). However, it must be recognised that this research contributes additional insights into these issues (Zanfardini, Simó and Alcañiz, 2013) in a Greek cultural context. Further research might explore these matters in a wider range of countries, with a larger sample size, and with a focus from a tourist perspective.

\section{References}

Apollo, M. (2017), "Conference report: ethics in tourism as a key to development, prosperity and well-being of all stakeholders: 3rd International Congress on ethics and tourism, Krakow, 27-28 April 2017", International Journal of Environmental Studies, Vol. 75 No. 2, pp. 1-5, available at: http://dx.doi.org/10.1080/00207233.20 17.1383076

Arvidsson, S. (2010), "Communication of corporate social responsibility: a study of the views of management teams in large companies”, Journal of Business Ethics, Vol. 96 No. 3, pp. 339-54.

Ashforth, B.E. and Gibbs, B.W. (1989), "The double-edge of organizational legitimation", Organization Science, Vol. 1 No. 2, pp. 177-94.

Bell, D. and Jayne, M. (2009), "Small cities? Towards a research agenda", International Journal of Urban and Regional Research, Vol. 33 No. 3, pp. 683-99.

Buckley, R. (2012), "Sustainable tourism: research and reality", Annals of Tourism Research, Vol. 39 No. 2, pp. 528-46.

Buhalis, D. (2001), "Tourism in Greece: strategic analysis and challenges", Current Issues in Tourism, Vol. 4 No. 5, pp. 440-80.

Chrysopoulos, P. (2016), "Greece ranks 4th in corruption among developed nations", available at: http://greece.greekreporter.com/2016/06/06/greece-ranks-4th-in-corruption-among-developed-nations/ (accessed 28 October 2017).

Enimerosi (2018), "The full 2018 programme of cruise ship arrivals in Corfu", available at: www.enimerosi. com/details_en.php?id=18143 (accessed 6 March 2018).

Farrington, T., Curran, R., Gori, K., O'Gorman, K.D. and Queenan, C.J. (2017), "Corporate social responsibility: reviewed, rated, revised", International Journal of Contemporary Hospitality Management, Vol. 29 No. 1, pp. 30-47.

GAN Integrity (2015), "Greece corruption report", available at: www.business-anti-corruption.com/countryprofiles/greece (accessed 28 October 2017).

Garay, L., Font, X. and Pereira-Moliner, J. (2017), "Understanding sustainability behaviour: the relationship between information acquisition, proactivity and performance", Tourism Management, Vol. 60, June, pp. 418-29.

Gaski, J. (1999), "Does marketing ethics really have anything to say? A critical inventory of the literature", Journal of Business Ethics, Vol. 18 No. 3, pp. 315-34.

Geolab Institute (2016), "Yellow tourism", available at: https://geolabinstitute.org/en/yellow-tourism/ytpublications/ (accessed 28 October 2017). 
Giannarou, L. (2017), "Cheating cabbies lie in wait of unsuspecting tourists", 17 July, available at: www. ekathimerini.com/220086/article/ekathimerini/community/cheating-cabbies-lie-in-wait-of-unsuspectingtourists (accessed 17 July 2017).

Graci, S. (2008), "What hinders the path to sustainability? A study of barriers to sustainable tourism development in Gili Trawangan, Indonesia", Pacific News, No. 29, January/February.

Greek City Times (2016), "Top 10 tourist destinations in Greece”, available at: https://greekcitytimes.com/top10-tourist-destinations-in-greece/ (accessed 8 November 2017).

Hamdouch, A., Demaziere, C. and Banovac, K. (2017), "The socio-economic profiles of small and medium-sized towns: insights from European case studies", Tijdschrift voor Economische en Sociale Geografie (Journal of Economic and Social Geography), Vol. 108 No. 4, pp. 456-71.

Hildreth, P. (2007), “The dynamics of 'place-shaping': the changing rationale for urban regeneration”, Journal of Urban Regeneration and Renewal, Vol. 1 No. 3, pp. 227-39.

Hofstede, G. (1980), Culture's Consequences, Sage, Beverly Hills, CA.

Hopkins, M. (1977), Corfu, B T Batsford Ltd, London.

Hosmer, L. (1994), "Strategic planning as if ethics mattered", Strategic Management Journal, Vol. 15 No. 52, pp. 17-34.

Hunt, S.D. and Vitell, S. (1986), "A general theory of marketing ethics", Journal of Macromarketing, Vol. 8 No. 1, pp. 5-16.

Hunt, S.D. and Vitell, S. (1993), "The general theory of marketing ethics: a retrospective and revision", in Smith, N.C. and Quelch, J.A. (Eds), Ethics in Marketing, Irwin, Homewood, IL, pp. 775-84.

Kim, M.J., Park, J.Y., Lee, C.-K. and Chung, J.Y. (2017), "The role of perceived ethics in the decision-making process for responsible tourism using an extended model of goal-directed behaviour", International Journal of Tourism and Hospitality Research, Vol. 31 No. 4, pp. 5-25.

Knowles, T. and Curtis, S. (1999), "The market viability of European mass tourist destinations. A poststagnation life-cycle analysis”, International Journal of Tourism Research, Vol. 1 No. 2, pp. 87-96.

Köseoglu, M.A., Sehitoglu, Y., Ross, G. and Parnell, J.A. (2016), "The evolution of business ethics research in the realm of tourism and hospitality: a bibliometric analysis", International Journal of Contemporary Hospitality Management, Vol. 28 No. 8, pp. 1598-621.

Lashley, C. and Rowson, B. (2010), "Lifestyle businesses: insights into Blackpool's hotel sector", International Journal of Hospitality Management, Vol. 29 No. 3, pp. 511-19.

Maignan, I. and McAlister, D.T. (2003), "Socially responsible organizational buying: can stakeholders dictate purchasing policies?", Journal of Macromarketing, Vol. 23 No. 2, pp. 78-89.

Mihalic, T. (2016), "Sustainable-responsible tourism discourse: towards 'responsustable' tourism”, Journal of Cleaner Production, Vol. 111, January, pp. 461-70.

Moorhouse, T., D'Cruze, N.C. and Macdonald, D.W. (2016), "Unethical use of wildlife in tourism: what's the problem, who is responsible, and what can be done?", Journal of Sustainable Tourism, Vol. 25 No. 4, pp. 505-16.

Morgan, R.M. and Hunt, S. (1994), "The commitment-trust theory of relationship marketing", Journal of Marketing, Vol. 58 No. 3, pp. 20-39.

Nill, A. (2003), "Global marketing ethics: a communicative approach", Journal of Macromarketing, Vol. 23 No. 2, pp. 90-104.

Panayiotopoulos, A., Patterson, M. and Burns, P. (2016), "(Re)thinking tourism discourse and place: beautific and horrific fantasies of tourism development in Faliraki, Rhodes", Proceedings of the 3rd Corfu Symposium on Managing \& Marketing Places, Corfu, 18-21 April.

Panayiotopoulos, A., Patterson, M. and Burns, P. (2017), "Local perceptions of mass tourists: the tourist gaze through the lenses of power", Proceedings of the 4th Corfu Symposium on Managing \& Marketing Places, Corfu, 24-27 April.

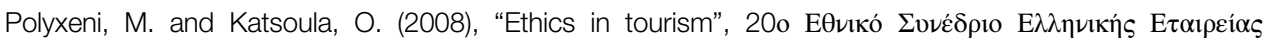

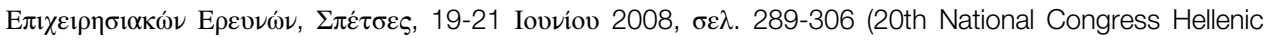
Society for Business Research, Spetses, 19-21 June, pp. 289-306). 
Popescu, O., Gentry Done, S. and Skinner, H. (2017), "Corfu PAWS", Proceedings of the 4th Corfu Symposium on Managing \& Marketing Places, Corfu, 24-27 April.

Power, S., Di Domenico, M.-L. and Miller, G. (2017), "The nature of ethical entrepreneurship in tourism", Annals of Tourism Research, Vol. 65, July, pp. 36-48.

Sainaghi, R., Phillips, P. and Zavarrone, E. (2017), "Performance measurement in tourism firms: a content analytical meta-approach”, Tourism Management, Vol. 59, April, pp. 35-56.

Servillo, L., Atkinson, R. and Hamdouch, A. (2017), "Small and medium-sized towns in Europe: conceptual, methodological and policy issues", Tijdschrift voor Economische en Sociale Geografie (Journal of Economic and Social Geography), Vol. 108 No. 4, pp. 365-79.

Sin, H.L. (2016), "Selling ethics: discourses of responsibility in tourism", Annals of the American Association of Geographers, Vol. 107 No. 1, pp. 218-34, doi: 10.1080/24694452.2016.1218266.

Singhapakdi, A., Marta, J.K.M., Rao, C.P. and Cicic, M. (2001), "Is cross cultural similarity an indicator of similar marketing ethics?", Journal of Business Ethics, Vol. 32 No. 1, pp. 55-68.

Skinner, H. (2005), "Towards a typology of virtuous marketing: applying marketing principles and practices to community development work”, The Marketing Review, Vol. 5 No. 3, pp. 263-76.

Skinner, H. (2014), "The future of tourism in Corfu: initial research, reporting, and beyond", Proceedings of the 1st Corfu Symposium on Managing \& Marketing Places, Corfu, 14-17 April.

Skinner, H. (2016), "World Tourism Day 2015 - Corfu discussions", Proceedings of the 3rd Corfu Symposium on Managing \& Marketing Places, Corfu, 18-21 April.

Skinner, H. (2017), "Editorial: responsible tourism and place making", Journal of Place Management and Development, Vol. 10 No. 2, pp. 102-5.

Sýkora, L. and Mulíček, O. (2017), "Territorial arrangements of small and medium-sized towns from a functional-spatial perspective", Tijdschrift voor Economische en Sociale Geografie (Journal of Economic and Social Geography), Vol. 108 No. 4, pp. 438-55.

Transparency International (2017), "Corruption perceptions index 2017", available at: www.transparency.org/ news/feature/corruption_perceptions_index_2017 (accessed 18 July 2018).

Tsartas, P. (2003), "Tourism development in Greek insular and coastal areas: sociocultural changes and crucial policy issues", Journal of Sustainable Tourism, Vol. 11 Nos 2/3, pp. 116-32.

Visvizi, A. (2016), "Greece, the Greeks, and the crisis: reaching beyond 'that's how it goes'”, Carnegie Council for Ethics in International Affairs, New York, NY, available at: www.carnegiecouncil.org/publications/articles_papers_ reports/787 (accessed 28 October 2017).

Williams, S. and Lew, A.A. (2015), Tourism Geography: Critical Understandings of Place, Space and Experience, 3rd ed., Routledge, Abingdon.

Williams-Burnett, N., Skinner, H. and Fallon, J. (2016), "Reality television portrayals of tourists behaving badly", Journal of Travel and Tourism Marketing, 20 December, Vol. 35 No. 3, pp. 336-47, doi: 10.1080/ 10548408.2016.1261757.

$\mathrm{Xu}$, Y. (2016), "A conceptual model of relationships between corporate social responsibility (CSR) and consumer behaviors", Tourism Travel and Research Association: Advancing Tourism Research Globally, Vol. 45, available at: https://scholarworks.umass.edu/ttra/2012/Oral/45 (accessed 21 November 2018).

Yin, R.K. (1989), Case Study Research: Design and Methods, Rev. ed., Sage Publications, Newbury Park, CA.

Yin, R.K. (1994), Case Study Research: Design and Methods, Applied Social Research Methods Series, Vol. 5, Rev. ed., Sage Publications, Newbury Park, CA.

Yin, R.K. (2009), Case Study Research: Design and Methods, Rev. ed., Sage Publications, Los Angeles, CA.

Yüksel, A., Yüksel, F., Culha, O., Güzel, B. and Işçi, C. (2015), "Centrally formed tourism development plans: attitudes and behaviours of excluded community members", in Nunkoo, R. and Smith, S.L.J. (Eds), Trust, Tourism Development and Planning, Contemporary Geographies of Leisure, Tourism and Mobility, Routledge, Abingdon, pp 111-42. 
Zanfardini, M., Aguirre, P. and Tamagni, L. (2013), "How is the evolution of CSR's research in tourism context? A review from 1992 to 2012", Proceedings of the 5th Advances in Tourism Marketing Conference, Vilamoura, 2-4 October.

Zanfardini, M., Simó, L.A. and Alcañiz, E.B. (2013), "Does perceived CSR prompt quality, satisfaction and loyalty to tourism destination?", Proceedings of the 5th Advances in Tourism Marketing Conference, Vilamoura, 2-4 October.

\section{Further reading}

Dias, J.A., López, F.M. and Correia, A. (2013), "Tourism second homes market - a course of owners' perspectives", Proceedings of the 5th Advances in Tourism Marketing Conference, Vilamoura, 2-4 October.

Levitt, T. (1958), "Are advertising and marketing corrupting society?", Advertising Age, 6 October.

\section{Corresponding author}

Heather Skinner can be contacted at: heatherskinnercorfu@gmail.com 